\title{
Macular cherry red spot is an important diagnostic marker in children with myoclonic epilepsies
}

\author{
Minal V. Kekatpure ${ }^{\mathrm{a}, 1}$, K.P. Vinayan ${ }^{\mathrm{a}, *}$, Sheela Nampoothiri ${ }^{\mathrm{b}}$, Gopal Pillai ${ }^{\mathrm{c}}$, Anand Kumar $^{\mathrm{d}}$ \\ ${ }^{a}$ Division of Pediatric Neurology, Department of Neurology, Amrita Institute of Medical Sciences, Kochi, Kerala, India \\ b Department of Genetics, Amrita Institute of Medical Sciences, Kochi, Kerala, India \\ ${ }^{\mathrm{c}}$ Department of Ophthalmology, Amrita Institute of Medical Sciences, Kochi, Kerala, India \\ ${ }^{\mathrm{d}}$ Department of Neurology, Amrita Institute of Medical Sciences, Kochi, Kerala, India
}

\section{A R T I C L E I N F O}

\section{Article history:}

Received 17 July 2016

Accepted 4 October 2016

Available online 29 October 2016

\section{Keywords:}

Cherry red spot

Symptomatic myoclonus

Gangliosidosis

Sialidosis

\begin{abstract}
A B S T R A C T
Symptomatic myoclonus is the major presenting feature of a small but very important and genetically diverse group of rare disorders included under the umbrella of progressive myoclonus epilepsy (PME) and progressive myoclonus ataxia (PMA) syndromes. These disorders often require extensive investigations to arrive at an accurate diagnosis. We present a case series highlighting the importance of a detailed fundoscopic eye examination; particularly when occurring in conjunction with a clinical history of myoclonus, developmental regression and other systemic features in clinching an etiologic diagnosis of storage disorder, specifically, gangliosidosis and sialidosis in children with suspected progressive myoclonus epilepsies. The causes of macular cherry red spot (CRS) on fundoscopic examination are limited and in a given child may provide an important clue for narrowing the differential diagnoses and finally making an accurate diagnosis. Current literature on symptomatic myoclonus, cherry red spot and their occurrence in PME/PMA syndromes is also reviewed.
\end{abstract}

(C) 2016 Published by Elsevier, a division of RELX India, Pvt. Ltd on behalf of Indian Epilepsy Society.

\section{Introduction}

Myoclonus may be an ominous symptom in children suggesting either a serious underlying disorder of the nervous system, a neurodegenerative disease or a systemic disorder. Such a myoclonus is termed as symptomatic or secondary myoclonus. ${ }^{1}$ Symptomatic myoclonus (SM) is the most common type of myoclonus, accounting for $72 \%$ of all myoclonus types. ${ }^{2}$ Various epilepsy syndromes, neurodegenerative disorders, post hypoxic state and progressive myoclonus epilepsies and ataxias (PME and PMA) are common well known causes of symptomatic myoclonus. SM is a highlighting feature of both PME (e.g. myoclonic epilepsy with ragged red fibers, dentatorubral pallidoluysian atrophy and storage disorders including neuronal ceroid lipofuscinosis, GM2 gangliosidosis, Gaucher disease) and PMA (e.g. in sialidosis type 1 and 2, Unverricht-Lundborg disease, etc.) syndromes, both of

\footnotetext{
* Corresponding author at: Division of Pediatric Neurology, Department of Neurology, Amrita Institute of Medical Sciences, Kochi 682041, Kerala, India E-mail address: vinayankp@aims.amrita.edu (K.P. Vinayan).

1 Current address: Department of Pediatric Neurology, Mazumdar Shaw Medical Center, Narayana Health City, Bengaluru 560099, Karnataka, India.
}

which are genetically heterogeneous and share many overlapping etiologies and phenotypic features. ${ }^{3,4}$

Macular cherry red spot (CRS) is one of the most dramatic finding on fundoscopic examination associated with only a handful of etiologic differential diagnoses; storage disorders being the most important group among them. ${ }^{5}$ Here we report a series of storage disorders in children clinically presenting as PME/PMA syndrome highlighting, the importance of a detailed fundoscopic examination as the simplest and quickest means of providing an etiologic clue in these disorders even in this era of diagnostic advances.

\section{Case presentations}

Case 1: A five month boy of non-consanguineous parentage (NCP) was brought with severe global developmental delay (GDD) and myoclonus. He was noted to have coarse facies, numerous Mongolian spots over back, and severe hypotonia. Abdominal examination revealed hepatosplenomegaly. Cardiac evaluation picked up a systolic murmur, confirmed echocardiographically to be caused by mitral valve regurgitation with prolapse. Skeletal survey ruled out presence of dysostosis multiplex. MRI Brain and Video Electroencephalogram (VEEG) were unremarkable. Fundus 
examination revealed bilateral CRS. A storage disorder, especially gangliosidosis, was considered. GM1 Gangliosidosis was confirmed by galactosidase assay (case: $0.9 \mathrm{nmol} / \mathrm{h} / \mathrm{mg}$; reference range: 80 $140 \mathrm{nmol} / \mathrm{h} / \mathrm{mg}$ ).

Case 2: A girl aged one year, born of NCP, was brought for evaluation of GDD. Marked hypotonia, stimulus sensitive myoclonus, bilateral macular CRS on fundoscopic examination were noted. Brain MRI revealed bilateral symmetrical hyperintensities of basal ganglia (BG). Other diagnostic tests including metabolic screen, peripheral smear, abdominal ultrasound, skeletal survey and neurophysiological tests including a VEEG were unremarkable. A diagnosis of storage disorder was considered, confirmed to be Tay Sachs disease by hexosaminidase A assay (case: $294 \mathrm{nmol} / \mathrm{h} /$ mg; control: $2400 \mathrm{nmol} / \mathrm{h} / \mathrm{mg}$ ).

Case 3: One-year old boy of consanguineous parentage, presented with neurodevelopmental regression preceded by an initial global developmental delay (GDD) and seizure onset at 10 months. He was initially diagnosed as mitochondrial disorder elsewhere. Upon examination hypotonia, stimulus sensitive myoclonus and visual impairment were evident. He had moderate hepatomegaly, confirmed by an abdominal ultrasound. Visual evoked potentials showed inconsistent waveforms. Brain MRI showed bilateral symmetrical basal ganglia hyperintensities. Presence of bilateral macular CRS on fundoscopy (Fig. 1) provided the key to an otherwise elusive diagnosis. Hexosaminidase A assay confirmed diagnosis of Tay Sachs disease (case: $429 \mathrm{nmol} / \mathrm{h} / \mathrm{mg}$, control: $1626 \mathrm{nmol} / \mathrm{h} / \mathrm{mg}$ ).

Case 4: A previously well thirteen and a half year old girl born of NCP presented with a syndrome of subacute onset ataxia, tremors and myoclonus at 11 years age which was initially managed with steroids elsewhere without much benefit. At her first visit to us, she was noted to have cerebellar signs, tremors, and significant incoordination. She was nonambulatory, barely standing with support due to very frequent myoclonus and ataxia. There were no corticospinal signs, neurocutaneous markers or organomegaly. Ocular examination was significant for bilateral nystagmus, while fundoscopy showed bilateral CRS. Her brain MRI, cerebrospinal fluid study, vasculitic and paraneoplastic work up, as well as metabolic screen were unremarkable. Neurophysiologically, VEP showed prolonged P100 latencies. Giant somatosensory evoked potential (SSEP) waveforms were striking. Prolonged VEEG showed no interictal epileptiform abnormalities. Very frequent generalized myoclonic jerks were recorded without electrographic correlation, suggesting a subcortical origin. The CRS, SM and ataxia were pointers toward a possible PMA disorder. The diagnosis of sialidosis as an underlying etiology for PMA was confirmed by

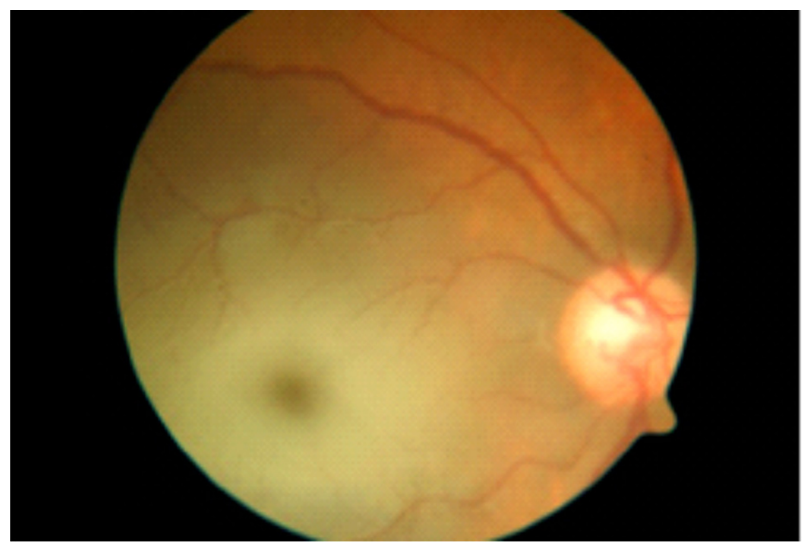

Fig. 1. Macular cherry red spot. Perifoveal yellow hue, accentuated foveal contour with macular CRS. deficient fibroblast neuraminidase activity (neuraminidase level in patient $0.4 \mathrm{nmol} / \mathrm{h} / \mathrm{mg}$; reference range: $20-120 \mathrm{nmol} / \mathrm{h} / \mathrm{mg}$ ).

\section{Discussion}

Storage disorders like GM1 gangliosidosis, Tay Sachs disease, as well as sialidosis come under the umbrella of the clinical syndrome of PME/PMA., ${ }^{6,7}$ All of them have an autosomal recessive inheritance. Hallmark features include developmental arrest, progressive neurological deterioration and psychomotor retardation, which are common. Facial dysmorphism, visceromegaly and skeletal dysplasia occur only in GM1 gangliosidosis, while progressive ataxia is a prominent feature of sialidosis. ${ }^{8}$ Each of these four cases had diverse presentations with underlying common features of myoclonus and macular CRS on fundoscopic examination; two salient features that led to an eventual diagnosis. The authors wish to highlight the diagnostic importance of a good clinical history and fundoscopic examination in PME/PMA syndromes by presenting this short case series, while briefly reviewing the literature on CRS and SM.

Symptomatic myoclonus (SM) is the commonest form of myoclonus often secondary to an underlying neurological or systemic disorder, and is often associated with other neurological symptoms like ataxia, extrapyramidal movements, cognitive decline, etc. Important neurometabolic and neurogenetic causes of SM are listed in Table 1.

Cherry red spot (CRS) is a dramatic finding, easily picked up on fundus examination. Its causes are limited. A simple way of etiologically classifying CRS is its association with neurometabolic versus non-neurometabolic conditions. Important non-neurometabolic causes for CRS include central retinal artery occlusion, traumatic retinal edema, Quinine and Dapsone toxicity, macular hemorrhage, macular hole with surrounding detachment, and Leber's congenital amourosis. When neurometabolic conditions

\section{Table 1}

Important neurometabolic and neurogenetic causes of symptomatic (secondary) myoclonus ${ }^{1}$ in children and adolescents.

\begin{tabular}{|c|c|}
\hline $\begin{array}{l}\text { A. Progressive myoclonic } \\
\text { epilepsy (including } \\
\text { storage disorders) }\end{array}$ & $\begin{array}{l}\text { 1. Unverricht-Lundborg disease } \\
\text { 2. Lafora body disease } \\
\text { 3. GM2 gangliosidosis (late infantile, juvenile) } \\
\text { 4. Tay-Sachs disease \& Sandhoff disease } \\
\text { 5. Gaucher disease (noninfantile neuronopathic) } \\
\text { 6. Sialidosis (types } 1 \text { and } 2 \text { ) } \\
\text { 7. Neuronal ceroid lipofuscinosis } \\
\text { 8. Myoclonic epilepsy with ragged red fibers. } \\
\text { 9. DRPLA } \\
\text { 10. Krabbe disease }\end{array}$ \\
\hline $\begin{array}{l}\text { B. Spinocerebellar } \\
\text { degenerations }\end{array}$ & $\begin{array}{l}\text { 1. Spinocerebellar ataxias (SCA) } \\
\text { 2. Friedreich ataxia } \\
\text { 3. Ataxia-telangiectasia } \\
\text { 4. Other spinocerebellar degenerations }\end{array}$ \\
\hline $\begin{array}{l}\text { C. Basal ganglia } \\
\text { degenerations }\end{array}$ & $\begin{array}{l}\text { 1. Wilson disease } \\
\text { 2. PKAN } \\
\text { 3. Huntington disease }\end{array}$ \\
\hline $\begin{array}{l}\text { D. Developmental } \\
\text { genetic disorders }\end{array}$ & 1. Rett Syndrome \\
\hline E. Metabolic disorders & $\begin{array}{l}\text { 1. Hypoglycemia (any etiology) } \\
\text { 2. Nonketotic hyperglycemia } \\
\text { 3. Multiple carboxylase deficiency } \\
\text { 4. Biotin deficiency } \\
\text { 5. Mitochondrial disorders }\end{array}$ \\
\hline $\begin{array}{l}\text { F. Exaggerated startle } \\
\text { syndromes }\end{array}$ & $\begin{array}{l}\text { 1. Hyperekplexia } \\
\text { 2. Episodic ataxia } \\
\text { 3. PKD } \\
\text { 4. Stiff Person Syndrome }\end{array}$ \\
\hline
\end{tabular}

Modified from Marsden et al. ${ }^{1}$

Abbreviations: DRPLA: dentatorubral pallidoluysian atrophy, PMA: progressive myoclonic ataxia, PKAN: pantothenate kinase-associated neurodegeneration, PKD: paroxysmal kinesigenic dyskinesia. 
Table 2

Neurometabolic conditions associated with the macular CRS. ${ }^{5,9}$

\begin{tabular}{|c|c|}
\hline Disorder & Deficient enzyme \\
\hline GM1 Gangliosidosis type $\mathrm{I}^{\mathrm{a}}$ & Galactosidase \\
\hline \multicolumn{2}{|l|}{ GM2 gangliosidosis } \\
\hline Tay Sachs ${ }^{\mathrm{a}}$ & Hexosaminidase A \\
\hline Sandhoff disease $\mathrm{e}^{\mathrm{a}}$ & Hexosaminidase $\mathrm{A}$ and $\mathrm{B}$ \\
\hline $\mathrm{AB}$ variant $\mathrm{c}^{\mathrm{c}}$ & Hexosaminidase A, B variant \\
\hline Late onset ${ }^{\mathrm{b}}$ & Partial Hexosaminidase A \\
\hline \multicolumn{2}{|l|}{ Niemann-Pick disease } \\
\hline Type $A^{c}$ & Sphingomyelinase \\
\hline Type B, C, $D^{\mathrm{b}}$ & Sphingomyelinase \\
\hline Metachromatic leukodystrophy ${ }^{\mathrm{b}}$ & Arylsulfatase A \\
\hline Mucolipidosis III $^{\mathrm{c}}$ & UDP N-AGA $^{\mathrm{d}}$ and N-AGA-1-PT ${ }^{\mathrm{e}}$ \\
\hline Farber's lipogranulomatosis ${ }^{\mathrm{a}}$ & Ceramidase \\
\hline \multicolumn{2}{|l|}{ Sialidoses } \\
\hline Cherry red spot myoclonus syndrome ${ }^{a}$ & Neuraminidase \\
\hline Nephrosialidosis ${ }^{\mathrm{c}}$ & Neuraminidase \\
\hline Galactosialidosis $^{\mathrm{a}}$ & $\begin{array}{l}\text { Protective protein } \\
\text { (galactosidase \& neuraminidase) }\end{array}$ \\
\hline Goldberg syndrome ${ }^{a}$ & $\begin{array}{l}\text { Neuraminidase, secondary } \\
\text { galactosidase }\end{array}$ \\
\hline
\end{tabular}

Abbreviations: CRS occurrence: a: common, b: rare, c: inconstant.

d Fibroblast enzyme UDP N-acetylglucosamine.

e Lysosomal enzyme N-acetylglucosamine-1-phosphotransferase.

are suspected, presence of CRS further narrows the differentials $s^{5,9}$ (Table 2).

A typical CRS has a pale hue resulting from heavy deposition of lipid, sphingolipid, or oligosaccharide material in ganglionic cells of retina at macula, where these cells are several layers thick. At the center of the pale region lies the foveal pit, which lacks ganglion cells, and thus continues to retain its reddish appearance. The normal foveal contour is accentuated across the pale background, giving rise to the characteristic appearance of CRS (Fig. 1). Concurrent with loss of perifoveal ganglion cells over time, CRS may completely disappear, evolving into optic atrophy. Alternately, the deposition of metabolic material may become more diffuse with progression of disease resulting in the loss of contrast and disappearance of the CRS. However loss of visual acuity without noticeable macular changes have been reported in Tay Sachs disease as well as GM1 gangliosidosis. ${ }^{9}$ Pitfalls in visualizing CRS include presence of roving eye movements, commonly seen in association with severe visual impairment; and non-cooperation in children, often necessitating ocular examination with mydriasis and occasionally under sedation. The characteristic cherry red appearance can be seen strikingly in Caucasians, but is sometimes difficult to visualize it in other ethnic populations due to the different "retinal complexion" or epithelial pigmentation. To overcome this issue, use of the term "Perifoveal white patch" has been suggested. ${ }^{10}$

\section{Conclusion}

Detailed fundoscopic evaluation is a key step in the etiological assessment of PME/PMA syndromes as it may help narrow down the differentials and initiate investigations along the right path to arrive at an accurate diagnosis. Exact diagnosis in neurogenetic disorders is crucial because of its direct implications on overall prognostication, decisions on available therapeutic options and need for genetic counseling.

\section{Funding}

None.

\section{Conflicts of interest}

The authors have none to declare.

\section{References}

1. Marsden CD, Hallett M, Fahn S. The nosology and pathophysiology of myoclonus. In: Marsden CD, Fahn S, eds. In: Movement Disorders. London: Butterworths; 1982:196-248

2. Caviness JN, Alving LI, Maraganore DM, Black RA, McDonnell SK, Rocca WA. The incidence and prevalence of myoclonus in Olmsted County, Minnesota. Mayo Clin Proc. 1999;74(6):565-569.

3. Marsden $\mathrm{CD}$, Harding AE, Obeso JA, Lu CS. Progressive myoclonic ataxia (the Ramsay Hunt syndrome). Arch Neurol. 1990;47:1121-1125.

4. Borg M. Symptomatic myoclonus. Neurophysiol Clin. 2006;36:309-318.

5. Taylor D. Neurometabolic diseases. In: Taylor D, ed. In: Pediatric Opthalmology 2nd ed. Boston, MA: Blackwell Science; 1997:772-793.

6. Wirrell E. Infantile, childhood, and adolescent epilepsies. Continuum. 2016; 22:60-93.

7. Satishchandra P, Sinha S. Progressive myoclonic epilepsy. Neurol India. 2010;58:514-522

8. Gravel RA, Kaback MM, Proia RL, Sandhoff K, Suzuki K, Suzuki K. The GM2 gangliosidoses. In: Scriver CR, Beaudet AR, Sly W, Valle D, eds. In: The Metabolic and Molecular Bases of Inherited Diseases 8th ed. New York: McGraw-Hill; 2001:38273876.

9. Kivlin JD, Sanborn GE, Myers GG. The cherry red spot in Tay-Sachs and other storage disorders. Ann Neurol. 1985;17:356-360.

10. Ospina LH, Lyons CJ, McCormick AQ. Cherry red spot or "Perifoveal white patch?". Can J Opthalmol. 2005;40:609-610. 